QUADERNS DE FILOSOFIA VOL. V NÚM. I (20I 8): 9I-99

eISSN: 234I-3042 DOI: IO.7203/QFIA.5.I.I 2474

Mirja Pérez de Calleja

Instituto de Investigaciones Filosóficas

Universidad Nacional Autónoma de México

\title{
Sobre la respuesta de Carlos Moya al Argumento de la Suerte
}

Resumen: Esta nota crítica se centra en el argumento de Carlos Moya (2017, 16870) a favor de la conclusión de que el Argumento de la Suerte representa en realidad un problema mayor para los compatibilistas que para los libertaristas. La Sección 1 introduce brevemente el Argumento de la Suerte. La Sección 2 discute la distinción de Moya entre dos concepciones de deliberación práctica, y propone una manera alternativa a la de Moya de entender la crítica al libertarismo que se basa en la condición de que cualquier decisión libre debe tener una explicación contrastiva. Finalmente, la Sección 3 resume la respuesta libertarista de Moya al Argumento de la Suerte, y sugiere un modelo alternativo de determinismo que Moya podría considerar para completar su argumento.

Abstract: This review focuses on Carlos Moya's (2017, 168-70) argument for the conclusion that the Argument from Luck actually represents a greater problem for compatibilism than for libertarianism. Section 1 briefly introduces the Argument from Luck. Section 2 discusses Moya's distinction between two conceptions of practical deliberation, and suggests a justification that Moya does not consider for the condition that any free decision must have a contrastive explanation. Finally, Section 3 summarizes Moya's libertarian response to the Argument from Luck, and suggests an alternative model of determinism that Moya might consider to complete his argument.

Palabras clave: libre albedrío, Argumento de la Suerte, libertarismo, compatibilismo, explicación contrastiva, determinismo.

Keywords: free will, Argument from Luck, libertarianism compatibilism, contrastive explanation, determinism. 
$\mathrm{E}$ $\mathrm{N}$ El CAPÍtulo 5 de su rico e iluminador ensayo El libre albedrío: un estudio filosófico, Carlos Moya desarrolla un argumento a favor de la conclusión de que el Argumento de la Suerte, normalmente considerado un problema para libertaristas, representa en realidad un problema mayor para los compatibilistas que para los libertaristas (Moya 20I7, 168-70). Esta nota crítica se centra en dos ideas que Moya desarrolla en el curso de este capítulo, que considero especialmente interesantes y fértiles: su distinción entre dos concepciones de deliberación práctica, que discuto en la Sección 2, y su respuesta libertarista al Argumento de la Suerte, de la que trata la Sección 3. Discuto estas ideas tras introducir brevemente el Argumento de la Suerte en la Sección 1.

\section{i. El Argumento de la Suerte contra el libertarismo}

Para explicar el Argumento de la Suerte, Moya (2017, 145-6) introduce el ejemplo de un juez encargado de un caso de corrupción política, que debe elegir entre dictar prisión preventiva para uno de los políticos investigados, o dejarlo en libertad con ciertas medidas cautelares. El juez decide, en pleno uso de sus facultades, tras haber reflexionado con calma sobre el asunto, y libre de presiones externas, dejar al acusado en libertad. Esta decisión cumple las condiciones libertaristas para la libertad de decisión, y en particular la condición de indeterminismo que postulan los libertaristas (a diferencia de los compatibilistas): el pasado hasta un momento antes de la decisión, junto con las leyes naturales, es compatible tanto con la decisión que el juez actualmente toma un momento después (dejar al acusado en libertad), como con la decisión, en ese momento, de dictar presión preventiva. Esta condición de indeterminismo implica que, en el momento en que el juez decide dejar al acusado en libertad, podría haber decidido dictar presión preventiva, tras deliberar exactamente como lo hace, con los poderes, capacidades, carácter moral, razones internas y motivos que tiene, y estando exactamente en el mismo estado mental en que está cuando decide dejarlo en libertad (146).

El problema es que, dado que nada en el pasado (y más concretamente nada concerniente al juez o a su modo de deliberar) explica por qué el juez elige una opción en lugar de la otra, parece una mera cuestión de azar (y de buena o mala suerte para el juez, dependiendo de si toma la decisión correcta) que, en el momento de decidir, el juez elija dejar al acusado en libertad en lugar de elegir enviarlo a prisión (146). En otras palabras, no existe una explicación contrastiva del hecho de que el agente elija la opción que elige en lugar de la otra opción que podría haber elegido (146-7), ya que, "por hipótesis, exactamente los mismos hechos que precedieron inmediatamente la decisión que el agente 
tomó habrían precedido la decisión contraria si el agente la hubiera tomado. Por ello, si la explicación contrastiva es necesaria para la responsabilidad moral por una decisión, la concepción libertarista de la decisión es incapaz de dar cuenta de dicha responsabilidad moral" (148).

Así pues, parece que el libertarista tiene un problema que el compatibilista no tiene. Al no postular una condición de indeterminismo para la libertad de decisión, el compatibilismo es coherente con la existencia de explicaciones contrastivas de las decisiones libres. "Puesto que, si el determinismo es verdadero, el pasado y las leyes implicaron lógicamente la decisión que el agente tomó, si hubiera tomado una decisión distinta, el pasado habría sido distinto, y el hecho de que el pasado fue como fue, y no de otro modo, explica que el agente tomara la decisión que tomó y no otra distinta” (148).

\section{DOS CONCEPCIONES DE LA DELIBERACIÓN PRÁCTICA}

Moya sugiere que el Argumento de la Suerte "asume implícitamente una interpretación cuasi literal del discurso sobre el peso o la fuerza de las razones" (163) similar a la de Hobbes (1651/1980). Moya (163) señala que esta concepción de las razones enlaza de modo natural con una determinada concepción de la deliberación, que atribuye a Levy $(2007,234)$. Según este modelo, "[d] eliberar consistiría, fundamentalmente, en medir y comparar el peso que las razones tienen para nosotros. Deliberar sería así sopesar razones. Y la decisión racional sería la que está avalada por la razón de mayor peso" (163, cursiva en el original). Pero, tal como seńala Moya (164), esta concepción de la deliberación se apoya en el dudoso supuesto de que las razones tienen ya un determinado peso o fuerza para el agente antes de que este empiece a deliberar, y que el agente se limita a descubrir, reflexionando, el peso relativo de sus diferentes razones internas, con el fin de elegir la opción que esté apoyada por razones de más peso. Frente a este modelo de la deliberación como un sopesar de razones, Moya favorece una concepción de la deliberación como "un proceso consistente en asignar peso a las razones, más que en registrar o medir el peso que ya poseen" (164, cursiva en el original). (Moya atribuye esta concepción alternativa de la deliberación a Robert Nozick (I98 I, 294), e incluye entre sus defensores a John Searle (200I), Patricia Greenspan (2012), David Wiggins (1978) y Robert Kane (1996).) Las razones de Moya para preferir esta concepción de la deliberación tienen que ver con un cierto tipo de decisiones, que Moya llama "elecciones escindidas".

Moya define una elección escindida como una "elección entre alternativas (mentir o decir la verdad, por ejemplo) respaldadas por razones de tipos 
distintos (digamos, razones de interés propio y razones morales) y con distinto valor moral" (162) que inclinan en direcciones opuestas con similar fuerza (165). A estas elecciones las caracteriza el hecho de que el agente se halla dividido entre varias opciones que ejemplifican diferentes objetivos y valores, y que están respaldadas por razones que son inconmensurables entre sí. En esto, las elecciones escindidas se distinguen de los casos Buridan, en que el agente no se halla escindido, pues se encuentra indiferente ante varias opciones que realizan igualmente bien un solo valor u objetivo (162). (El asno del ejemplo que originariamente usó Buridan para ilustrar estos casos se hallaba exactamente a la misma distancia de dos pilas de heno igualmente apetitosas, incapaz de decidir en qué dirección caminar.)

En casos Buridan, las razones que el agente reconoce para elegir diferentes opciones son del mismo tipo y, desde la perspectiva del agente, justifican igualmente bien las elecciones que respectivamente apoyan (161). Por lo tanto, según Moya, en estos casos es "perfectamente razonable" (161) y "racional" (165) elegir una opción arbitrariamente, por ejemplo lanzando una moneda al aire. (Lo irracional sería no elegir ninguna opción, como hizo el asno de Buridan, que murió de inanición.)

Moya (165) sugiere que el Argumento de la Suerte se basa en una concepción de la deliberación como un proceso de medir el peso pre-establecido de las razones, concepción que, según Moya, trata las elecciones escindidas como si fueran elecciones Buridan. El modelo de la deliberación como un sopesar de razones asume que, dado el punto de vista del sujeto, cada razón, sea del tipo que sea (moral, prudencial, etc.), tiene un peso determinado; y esto equivale a establecer una medida común para calibrar razones de distintos tipos, haciendo que todas las razones se traten como razones conmensurables entre sí (165). $\mathrm{Si}$ a razones de diferentes tipos se les pudiesen siempre asignar pesos relativos, asignando a cada razón un peso relativo respecto a cualquier otra, entonces una elección escindida sería esencialmente un caso Buridan, en que no hay una sola opción respaldada por razones de más peso que las que respaldan las opciones alternativas, sino varias opciones respaldadas por razones de igual peso. Si esta fuera realmente la situación, entonces sería razonable y responsable, en casos escindidos, elegir una opción al azar lanzando una moneda al aire (165).

Sin embargo, dice Moya $(162,165)$, no es razonable ni responsable, sino "frívolo, arbitrario e irracional (o a-racional)" (162) elegir lanzando una moneda al aire entre mentir y decir la verdad, o entre dictar arresto preventivo y dejar a un acusado en libertad. En casos escindidos, elegir una opción lanzando una moneda sería "una frivolidad seguramente incompatible con la condición del agente moralmente responsable" (162), puesto que, en estos casos, las razones que el agente reconoce como justificaciones para elegir diferentes opciones no 
son del mismo tipo $(162,165)$. Así, el modelo de la deliberación como un sopesar de razones no puede sino concebir las elecciones escindidas como arbitrarias y a-racionales (165), "dado que, por hipótesis, el peso es el mismo en casos de elección escindida, pero al mismo tiempo se trata de razones dispares en su contenido" (165).

Por tanto, si bien el modelo de la deliberación práctica como un proceso de sopesar razones se aplica sin problemas a casos Buridan, no parece un modelo adecuado para elecciones escindidas (165). En casos en que el peso relativo de cada razón no es determinable partiendo de hechos sobre el agente, porque las razones, al ser de distintos tipos, son inconmensurables, el agente tiene que decidir qué peso relativo otorgar a las diferentes consideraciones (165-6).

Moya recomienda al libertarista adoptar, al menos para casos de elección escindida, el modelo de la deliberación práctica como un proceso de asignar pesos relativos a diferentes razones, y no de medir o descubrir los pesos relativos de las diferentes razones (165). Esta concepción subraya la inconmensurabilidad de diferentes tipos de razones en casos escindidos, y por tanto el hecho de que "no hay posibilidad de sopesarlas, sino que hemos de asignarles peso" (165), privilegiando así, allí y entonces, las razones de tipo moral sobre las de tipo prudencial, por ejemplo (165-6). En casos de elección escindida, decidir es asignar definitivamente, allí y entonces, más peso a las razones que apoyan esa opción que a las razones inconmensurables que apoyan opciones contrarias (166). Según Moya (166), esta identificación de la decisión con la asignación definitiva de peso a ciertas razones restablece el vínculo entre razones y decisión que el Argumento de la Suerte ponía en duda en el caso de decisiones escindidas que satisfacen las condiciones libertaristas de indeterminismo.

Moya (166-7) reconoce que identificar una elección escindida con una asignación de peso a razones no implica que haya, ni ayuda a encontrar, una explicación contrastiva de las elecciones escindidas. Por tanto, esta concepción de las elecciones escindidas no constituye una respuesta al Argumento de la Suerte (166). Sin embargo, dice Moya, postular en este contexto que toda elección libre tiene una explicación contrastiva parece prejuzgar la cuestión en contra del libertarista (167). En palabras de otro artículo donde Moya desarrolla este argumento, "si lo que el crítico está realmente demandando cuando requiere explicaciones contrastivas como condición de la racionalidad de la elección son condiciones causalmente suficientes de la elección, está claramente prejuzgando la cuestión en contra del libertarista; pues está dando por supuesto que solamente las decisiones causalmente determinadas pueden ser racionales" (Moya 20 I 5, 87, cursiva en el original).

Considero muy atractiva la concepción de Moya de la deliberación práctica, y encuentro convincente su argumento de que este modelo es el más 
adecuado para casos escindidos. Este modelo captura el hecho de que decidir cuando uno está escindido involucra un acto fundamental e irreducible de comprometerse a una asignación de peso a razones. Pero pienso que la discusión de Moya sería más completa si considerara la siguiente manera de entender la exigencia de explicaciones contrastivas de quien usa el Argumento de la Suerte contra el libertarista. Lo que el crítico está demandando cuando requiere explicaciones contrastivas es que se cumpla la siguiente condición, cuya satisfacción es compatible con el hecho de que la decisión no esté determinada por sus antecedentes causales. Para que una decisión (incluso si es escindida) sea libre, debe haber un factor diferencial mental en las causas próximas de la decisión que explique por qué el agente elige la opción que elige en lugar de otra, apelando al modo en que alguna razón interna o motivación aparece ante el agente cuando este está a punto de decidirse. Esta condición es compatible con situaciones en que el agente está dividido entre opciones igualmente atrayentes de valores inconmensurables, ya que uno puede estar escindido pero a la vez no ser psicológicamente capaz de decidir algo distinto sin antes considerar algún hecho con mayor detenimiento, o recordar con vividez algo que uno no tenía presente, o algo por el estilo. Y, si estar escindido entre opciones igualmente atractivas de valores inconmensurables es compatible con afirmar un juicio reflexivo sobre qué opción es la mejor, un juicio tal es un factor diferencial incluso más claramente apropiado para eliminar la suerte del agente sobre qué opción elige cuando se encuentra escindido — claramente apropiada, desde la perspectiva del defensor de la condición de que, para que una decisión (incluso si es escindida) sea libre, debe tener una explicación contrastiva que apele a algún factor diferencial psicológico- ¿ ¿Qué diría Moya si se entendiera así la motivación para adoptar esta condición en que se basa el Argumento de la Suerte contra el libertarismo?

\section{Respuesta libertarista de Moya al Argumento de la Suerte}

La respuesta de Moya (168-70) al Argumento de la Suerte entendido como un argumento contra el libertarismo es que, si el mundo fuera determinista y todas las decisiones estuvieran causalmente determinadas, no por ello dejaría de haber elecciones escindidas, ya que el determinismo no implica que una persona no pueda estar internamente escindida entre diferentes razones; y estas decisiones, a pesar de estar determinadas, serían una cuestión de azar y suerte (169). Una decisión escindida en un mundo determinista es, como todo lo demás, cuestión de necesidad causal (168), ya que está causalmente determinada por factores antecedentes, que figuran en explicaciones contrasti- 
vas de la decisión (169). Pero las explicaciones contrastivas de estas decisiones escindidas determinadas, al no poder deberse a razones del agente (que, por hipótesis, inclinan con similar fuerza en direcciones opuestas), deben de hallarse "en algún factor distinto de las razones del agente, tal vez en algún suceso o estado neurológico o psicológico más allá de su conciencia” (169). Y factores diferenciales a-racionales de este tipo, que no están bajo el control del agente sino que son cuestión de suerte para él, son incluso más hostiles al control racional que la ausencia de factores diferenciales para decisiones de distintos contenidos (169). (Mark Balaguer (2010) defiende un argumento contra el compatibilismo con paralelismos a este, aunque desde una perspectiva significativamente diferente, y sin entender su argumento como una versión del Argumento de la Suerte.)

Así, Moya (170) concluye que el hecho de que el determinismo implique factores diferenciales a-racionales para elecciones escindidas de contenidos opuestos hace de un mundo determinista un lugar más hostil para el control racional sobre decisiones escindidas que un mundo indeterminista en que se cumplen las condiciones libertaristas para la libertad de decisión. Al menos si el mundo es indeterminista de un modo que cumple las condiciones libertaristas, y las elecciones escindidas son asignaciones definitivas de peso a ciertas razones alli y entonces por el agente, no hay factores a-racionales que ocultamente hagan que el agente elija la opción que elige en lugar de otra (170).

Estoy de acuerdo con Moya en la importancia de subrayar que no toda explicación contrastiva en términos de eventos mentales y agenciales implica un mayor control racional del agente sobre su decisión. Pero, tal y como he sugerido en la discusión sobre diferentes concepciones de la deliberación práctica, quizás Moya debería considerar en este punto una teoría según la cual hay libertad de decisión sobre elecciones escindidas solo si hay un factor diferencial en las causas mentales de cada elección psicológicamente posible, no a-racional, sino ligado a razones y motivaciones aceptadas por el agente. La manera en que diferentes razones y motivaciones se le presentan al agente podría proveer distintos factores diferenciales apropiados para eliminar la suerte del agente sobre el hecho de elegir una opción en lugar de otra. Y quizás procesos inconscientes dependientes de razones conscientes podrían también constituir factores diferenciales apropiados. Finalmente, si las elecciones escindidas son compatibles con afirmar un juicio sobre qué opción es la mejor, un juicio tal sería todavía mejor candidato a factor diferencial apropiado para constituir una condición necesaria para la libertad de decisión en casos escindidos.

Por otro lado, pienso que el argumento de Moya sería más completo si considerara también un modelo de determinismo según el cual la diferencia en el pasado que explica contrastivamente las decisiones escindidas y de tipo 
Buridan es una diferencia microfísica en las cadenas de eventos frágiles que constituyen los realizadores de la decisión, en la que no superviene ninguna diferencia neuronal (ni, por tanto, psicológica). En este modelo, el determinismo no implica que haya un factor diferencial a-racional en las causas inmediatas de cada decisión escindida que explica por qué el agente elige la opción que elige en lugar de otra.

Así, en este modelo, el determinismo no implica que siempre haya explicaciones contrastivas de las decisiones en términos de su contenido: si descubriésemos que el mundo es determinista o indeterminista, esto no tendría implicaciones relativas a las explicaciones contrastivas de nuestras decisiones con respecto a decisiones alternativas de contenidos opuestos. En particular, según este modelo, no es cierto que si el determinismo es verdadero hay factores diferenciales ocultos en todas las transacciones causales en que no hay factores diferenciales conocidos. Si este modelo de determinismo es correcto, el determinismo no es más hostil a la libertad de decisión en casos escindidos que un indeterminismo como el que exigen los libertaristas, al menos no por las razones que Moya ofrece. 


\section{BIBLIOGRAFÍA}

Balaguer, M. 20io, Free Will as an Open Scientific Problem, Cambridge, MA: MIT Press.

Greenspan, P. 20 1 2, "Free Will and Rational Coherency", Philosophical Issues, 22 (Action Theory): 185-200.

Hobbes, T. i651/1980, Leviatán, C. Moya y A. Escohotado (ed.), Madrid: Editora Nacional.

Kane, R. I996, The Significance of Free Will, Nueva York: Oxford University Press. Levy, N. 2007, Neuroethics: Challenges for the 21st Century, Cambridge: Cambridge University Press.

Moya, C. 2017, El libre albedrio: un estudio filosófico,

Moya, C. 2015, "Libertad, Determinismo y Responsabilidad Moral", en J. L. Prades (ed.), Cuestiones de Metafísica, Madrid: Tecnos.

Nozick, R. I98 I, Philosophical Explanations, Oxford: Clarendon Press.

Searle, J. 200I, Rationality in Action, Cambridge, MA: MIT Press.

Wiggins, D. I978, “Deliberation and Practical Reason”, en J. Raz (ed.), Practical Reasoning, Oxford: Oxford University Press. 
